\title{
Lack of detectable short-term effects of a single dose of ivermectin on the human immune system
}

Natalie E. Wilson ${ }^{1,2}$, Barbara J. Reaves ${ }^{1,2}$ and Adrian J. Wolstenholme ${ }^{1,2,3^{*}}$

\begin{abstract}
Background: Ivermectin is widely used in human and animal medicine to treat and prevent parasite nematode infections. It has been suggested that its mode of action requires the host immune system, as it is difficult to reproduce its clinical efficacy in vitro. We therefore studied the effects of a single dose of ivermectin (Stromecto ${ }^{\circledR}-0.15 \mathrm{mg} / \mathrm{kg}$ ) on cytokine levels and immune cell gene expression in human volunteers. This dose reduces bloodstream microfilariae rapidly and for several months when given in mass drug administration programmes.
\end{abstract}

Methods: Healthy volunteers with no travel history to endemic regions were given 3-4 tablets, depending on their weight, of either ivermectin or a placebo. Blood samples were drawn immediately prior to administration, $4 \mathrm{~h}$ and $24 \mathrm{~h}$ afterwards, and complete blood counts performed. Serum levels of 41 cytokines and chemokines were measured using Luminex ${ }^{\circledR}$ and expression levels of 770 myeloid-cell-related genes determined using the NanoString nCounter ${ }^{\circledR}$. Cytokine levels at $4 \mathrm{~h}$ and $24 \mathrm{~h}$ post-treatment were compared to the levels pre-treatment using simple $t$ tests to determine if any individual results required further investigation, taking $p=<0.05$ as the level of significance. NanoString data were analysed on the proprietary software, nSolver ${ }^{\mathrm{TM}}$.

Results: No significant differences were observed in complete blood counts or cytokine levels at either time point between people given ivermectin versus placebo. Only three genes showed a significant change in expression in peripheral blood mononuclear cells $4 \mathrm{~h}$ after ivermectin was given; there were no significant changes $24 \mathrm{~h}$ after drug administration or in polymorphonuclear cells at either time point. Leukocytes isolated from those participants given ivermectin showed no difference in their ability to kill Brugia malayi microfilariae in vitro.

Conclusions: Overall, our data do not support a direct effect of ivermectin, when given at the dose used in current filarial elimination programmes, on the human immune system.

Trial registration ClinicalTrials.gov NCT03459794 Registered 9th March 2018, Retrospectively registered https://clinicaltr ials.gov/ct2/show/NCT03459794?term $=$ NCT03459794\&draw $=2 \&$ rank $=1$.

Keywords: Ivermectin, Lymphatic filariasis, Peripheral blood mononuclear cells, Polymorphonuclear cells, Cytokine

*Correspondence: adrianw@uga.edu

1 Department of Infectious Diseases, University of Georgia, Athens, GA 30602, USA

Full list of author information is available at the end of the article

\section{Introduction}

Ivermectin is a key part of mass drug administration programmes for the control and eventual elimination of the major tropical diseases lymphatic filariasis (LF) and onchocerciasis, and as such is given to hundreds of millions of people every year [1-4]. Ivermectin treatment 
of people infected with the filarial nematodes that cause these diseases results in a rapid removal of microfilariae (Mf) from the circulation or skin of LF and onchocerciasis patients, respectively $[4,5]$. The replacement of these Mf by the adult female parasites is also suppressed for many months by the drug treatment due to the embryostatic action of the drug [5], which may be due to the expression of ivermectin-sensitive glutamate-gated chloride channels in the reproductive tissues of adult females [6]. However, in vitro, concentrations of ivermectin equivalent to the peak plasma concentrations found following treatment have little or no measurable effect on Mf motility or viability [7-10]. This has led to the hypothesis that the effect of ivermectin on Mf depends in part on the host immune system [11], and some direct evidence to support this hypothesis has been obtained from studies on related animal parasites. For example, ivermectin killing of Litomosoides carinii (now L. sigmodontis) Mf in vitro was dependent on the addition of rat spleen cells [9], and this observation was later extended to neutrophils, with the ivermectin-dependent killing postulated to require nitric oxide, but not physical attachment [12]. We have previously reported that the binding of canine polymorphonuclear cells (PMNs) and peripheral blood mononuclear cells (PBMCs) to Dirofilaria immitis Mf in vitro increases in the presence of ivermectin [13], and this correlates with the drug-resistance status of the parasite [14]. Human PMNs and PBMCs can also bind and kill Brugia malayi Mf [15], though this depends on the batch of parasites used in the assay and may reflect their overall condition [16]. Taken together, these and other data could be interpreted to suggest that ivermectin has an effect not only on the parasite, but also on the host immune system [17].

The anthelmintic action of ivermectin and the other macrocyclic lactones is accepted to be due to its specific action on glutamate-gated chloride channels [18-20], at which it acts as an unconventional agonist, opening the channels slowly and effectively irreversibly [21-23]. These channels are unique to invertebrates; however, related ivermectin-sensitive channels are expressed widely in the mammalian nervous system [24] and other tissues, including on some cells of the immune system [25]. Indeed, the sensitivity of neuronal ligand-gated channels to ivermectin is the reason for the increased susceptibility of mdr-1 deficient animals to ivermectin intoxication [26]. In addition, it has more recently become apparent that ivermectin can affect multiple molecular targets in mammals, including P2X receptors and the farnesoid X receptor (FXR) [27, 28]. Ivermectin has also been shown to have anti-inflammatory properties in $\mathrm{T}$ cell-mediated skin disease, and this effect was independent of any effect on ligand-gated chloride channels or FXR, suggesting an additional, so far unidentified, target [29]. The drug has antiviral properties and has even been suggested as a potential therapy for COVID-19 [30, 31], though the drug concentrations at which the anti-viral effect becomes apparent are considerably higher than those found in the plasma of MDA recipients.

If the microfilaricidal action of ivermectin is due, at least in part, to the drug facilitating immune clearance of the parasites then this could be due to one of two general mechanisms, or a combination of them. There are several reports indicating that the drug can interfere with secretion and vesicle release from the parasites, which has been hypothesized to inhibit their ability to evade host immunity [32, 33], and recently these extracellular vesicles were demonstrated to downregulate the phosphorylation of mTOR in a human monocyte-derived cell line [34]. Alternatively, ivermectin could have a direct effect on the host immune system. This second hypothesis predicts that ivermectin treatment of uninfected people should result in measurable changes in immune function or in gene expression. In the experiments reported here, we have attempted to test this prediction. Such an effect could also be reflected in an increased ability of the treated immune cells to recognize and kill the parasites, and so we have also examined whether the ivermectin altered the ability of human leukocytes to kill B. malayi Mf in vitro.

\section{Materials and methods \\ Ivermectin administration to human volunteers and sample collection}

Twelve volunteers, aged between 18 and 65 and weighing between 50 and $84 \mathrm{~kg}$, were recruited from the Athens, Georgia, area. Inclusion and exclusion criteria are listed in Additional File 1. Subjects attended the University of Georgia Clinical and Translational Research Unit (CTRU) twice. They were asked to fast for at least 3-4 h prior to the first visit. At that visit, they were weighed and allocated to groups by CTRU staff using a block randomization protocol. $18 \mathrm{ml}$ of blood (Samples A) were drawn in a fasting state and subjects were administered $150 \mu \mathrm{g} /$ $\mathrm{kg}$ Stromectol ${ }^{\circledR}$ as three or four tablets or the equivalent number of placebo tablets immediately after blood was drawn. Participants remained at CTRU for four hours then another $15 \mathrm{ml}$ of blood (Samples B) was drawn. A third blood sample ( $18 \mathrm{ml})$-Samples C-was drawn $24 \mathrm{~h}$ after administration of the drug. All the subjects completed the study. All samples were coded immediately after being taken and all analyses completed blind. Serum was prepared from 5 to $10 \mathrm{ml}$ of blood collected as above but allowed to clot in the absence of heparin or EDTA (incubated for $\sim 2 \mathrm{~h}$ at room temperature). The liquid 
fraction of the blood sample was removed to a fresh tube and centrifuged at $10,000 \times g$ for $5 \mathrm{~min}$. The resulting supernatant was filter sterilized.

\section{Complete blood counts}

Complete blood counts $(\mathrm{CBC})$ were carried out by the Clinical Pathology laboratory at Piedmont Athens Regional Hospital.

\section{Cytokine measurements}

Human cytokine and chemokine levels were measured on a Luminex MAGPIX ${ }^{\circledR}$ instrument using the Milliplex Human Cytokine/Chemokine Magnetic Bead Premixed 41 Plex Kit (EMD Millipore, Billerica MA, USA). All samples were measured using three technical replicates, with two replicates of all standards and controls.

\section{Gene expression analysis}

PBMCs and PMNs were purified, and RNA extracted from cells isolated from each individual subject as described previously [15]. Neutrophils were isolated using the EasySep ${ }^{\mathrm{TM}}$ Direct Human Neutrophil Isolation Kit (STEMCELL Technologies, Vancouver, BC, Canada) according to manufacturer's instructions. PBMCs were isolated using SepMate ${ }^{\mathrm{TM}}-50$ Tubes (STEMCELL Technologies, Vancouver, BC, Canada) according to manufacturer's instructions. To remove contaminating platelets, the optional extended wash step $(120 \times g$ for $10 \mathrm{~min})$ of the SepMate ${ }^{\mathrm{TM}}$ protocol was included. Isolated PMNs and PBMCs were washed in PBS (centrifuged at $300 \times g$ for $5 \mathrm{~min}$ ), re-suspended in a 1:1 mixture of RPMI-1640$10 \mathrm{mM}$ HEPES buffer and autologous serum, stored at room temperature, and used within $6 \mathrm{~h}$ post-isolation. Cell counts were performed on a 1:10 dilution of each preparation of cells containing 0.4\% trypan blue (Gibco, Life Technologies, Grand Island, NY, USA) using a BioRad $\mathrm{TC}_{10}{ }^{\mathrm{TM}}$ automated cell counter (BioRad, Hercules, CA, USA). To extract RNA, $0.75 \mathrm{ml}$ TRIzol was added per $0.25 \mathrm{ml}$ sample $\left(5-10 \times 10^{6}\right.$ cells). Cells were lysed by pipetting up and down. Homogenized samples were incubated for $5 \mathrm{~min}$ at room temperature. Chloroform $(0.2 \mathrm{ml} / 1 \mathrm{ml}$ TRIzol) was added and the sample shaken for $15 \mathrm{~s}$ followed by a 3-min incubation at room temperature. Samples were centrifuged at $12,000 \times g$ for $15 \mathrm{~min}$ at $4{ }^{\circ} \mathrm{C}$. The aqueous phase was removed, and the RNA precipitated by adding $0.5 \mathrm{ml}$ isopropanol (including $15 \mu \mathrm{g}$ GlycoBlue $^{\mathrm{TM}}$ coprecipitant, Invitrogen, Carlsbad, CA) to the aqueous phase and incubating at room temperature for $10 \mathrm{~min}$. After centrifugation at $12,000 \times g$ for $10 \mathrm{~min}$ at $4{ }^{\circ} \mathrm{C}$, the supernatant was removed and the pellet washed in $1 \mathrm{ml} 75 \%$ ethanol per $1 \mathrm{ml}$ TRIzol. After a brief vortex, the sample was centrifuged at $7500 \times g$ for $5 \mathrm{~min}$ $\left(4{ }^{\circ} \mathrm{C}\right)$. Ethanol was removed and the pellet air-dried for
5-10 min prior to resuspending in RNase-free water. The expression levels of 770 genes for each individual subject were measured on an nCounter ${ }^{\circledR}$ SPRINT molecular profiling system, using the nCounter ${ }^{\circledR}$ Human Innate Immunity Myeloid Panel.

\section{Microfilarial killing}

PBMCs and PMNs were isolated from the samples A and $\mathrm{C}$ and incubated with freshly isolated $B$. malayi $\mathrm{Mf}$ as previously described [15]. Briefly, assays were set up in Corning ${ }^{\circledR}$ 96-well TC-treated microplates (MilliporeSigma, Burlington, MA, USA). Four components were added to each well in $50 \mu \mathrm{l}$ volumes, giving a total volume of $200 \mu \mathrm{l}: \sim 100 \mathrm{~B}$. malayi Mf, autologous serum and either no cells, $\sim 150,000$ PMNs, or $\sim 150,000$ PBMCs. To create the respective controls, $50 \mu \mathrm{l}$ of RPMI-1640 was substituted for the relevant component. The tissue culture plates were incubated at $37{ }^{\circ} \mathrm{C}$ and $5 \% \mathrm{CO}_{2}$. Viable Mf were counted on a Nikon ${ }^{\text {TM }}$ TS2 microscope (Nikon Instruments Inc., Melville, NY, USA) at 1, 24 and $120 \mathrm{~h}$ post-experimental set up. Mf were considered to be 'viable' if there was any detectable movement observed within approximately $10-20 \mathrm{~s}[8,15]$.

\section{Statistical analysis}

The mean numbers of each cell type were calculated for each arm at $24 \mathrm{~h}$ post-treatment and compared to those in the pre-treatment samples using a simple $t$ test, with $p=<0.05$ as the level of significance. Since none of the measurements passed this test, no further analysis was performed. Cytokine levels were obtained from the Luminex data. The mean level plus or minus standard error of each analyte were calculated for each arm at each time point $(0,4,24 \mathrm{~h}$ post-treatment). For the control and ivermectin arms, levels at $4 \mathrm{~h}$ and $24 \mathrm{~h}$ post-treatment were compared to the levels pre-treatment using simple $t$ tests to determine if any individual results required further investigation, taking $p=<0.05$ as the level of significance. The change in levels $4 \mathrm{~h}$ and $24 \mathrm{~h}$ post-treatment were also compared between the placebo- and ivermectin-treated groups. Since none of the individual analyte results met this criterion, no further analysis was carried out. The NanoString data were analysed on the proprietary software, nSolver ${ }^{\mathrm{TM}}$ (NanoString Technologies, Inc., Seattle, WA, USA). The data passed quality control criteria. The software calculated the $\log _{2}$ geometric mean levels of each mRNA measured and used $t$ tests to determine statistically significant changes in expression between 4 and $24 \mathrm{~h}$ post-treatment for the control and ivermectin arms. We also compared the changes in expression at $4 \mathrm{~h}$ and $24 \mathrm{~h}$ post-treatment between the placebo- and ivermectin-treated groups. The BenjaminiYekutieli false discovery rate [35] method was used to 
account for the expectation that significant changes in genes may be correlated with or dependent on each other, and the subsequent resulting false discovery rate adjusted $p$-value of $<0.05$ used to determine those changes that were deemed to be statistically significant. In all the analyses, each individual subject was treated as a biological replicate, giving $N=4$ for the placebo arm and $N=8$ for the ivermectin arm.

\section{Results}

\section{Complete blood counts}

After completion of all the experimental measurements, the coding was broken and we found that four of the participants received the placebo and eight received ivermectin. A comparison of the $\mathrm{CBC}$ results from the two groups (Fig. 1) revealed no significant differences between them $24 \mathrm{~h}$ after drug administration.

\section{Cytokine levels}

We measured the levels of 41 cytokines and chemokines in all the samples using the Milliplex Human Cytokine/ Chemokine MAGNETIC BEAD Premixed 41 Plex Kit and compared the levels at 4 and $24 \mathrm{~h}$ post-treatment to pre-treatment levels between the two groups (Fig. 2). This analysis was complicated by several factors. There were large individual variations in the levels of many cytokines pre-treatment. (For many analytes, at least one sample was below the limit of detection preventing a comparison of the mean levels between treatment groups, and the detection of any changes from the baseline measurement.) Several analytes seemed to show a diurnal variation in the placebo group, as previously reported [36-39], as evidenced by changes in levels, usually increases,

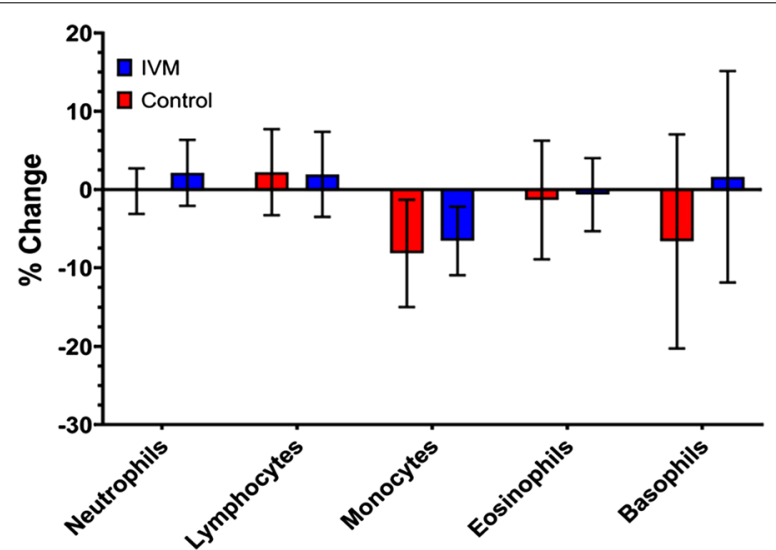

Fig. 1 Complete blood counts show no significant changes $24 \mathrm{~h}$ following ivermectin administration. The mean\% change in each cell type between Samples C and A is shown; error bars indicate the SEM. Ivermectin-treated subjects are in blue, placebo-treated subjects in red between $t=0$ and $t=4$ in the control group (Fig. 2A). Overall, there were no significant differences in the levels of any of the substances tested between the ivermectin-treated and control groups at either $4 \mathrm{~h}$ or $24 \mathrm{~h}$ post-treatment.

\section{Gene expression}

We extracted RNA from purified PMNs and PBMCs isolated from each of the experimental subjects and measured the expression of 770 transcripts in all these samples using NanoString technology and the nCounter ${ }^{\circledR}$ Human Innate Immunity Myeloid Panel. The only statistically significant differences were found in the 4-h post-treatment PBMC samples (Fig. 3), where there were three transcripts that showed a reduction in expression: platelet-activating factor receptor, prokineticin 2 , and histone deacetylase 5 (Table 1). There were no changes in the expression of any of these transcripts in the PMNs at either time point, or in the PBMCs at $24 \mathrm{~h}$ post-treatment (Fig. 3) (Additional Files 2, 3, 4, 5).

\section{Leukocyte killing of Brugia malayi microfilariae}

Since we have previously shown that human PMNs and PBMCs can kill $B$. malayi Mf in vitro, we tested the effect of the ivermectin treatment on the ability of leukocytes isolated $24 \mathrm{~h}$ after treatment to do this (Fig. 4). We observed no reduction in the survival of $\mathrm{Mf}$ incubated with PMNs or PMNs + PBMCs from subjects given ivermectin, compared with those from the control subjects.

\section{Discussion}

Ivermectin is an extremely potent and effective drug, which rapidly removes microfilaria from the circulation and tissues of infected patients. It has been speculated that this rapid clearance of microfilariae involves the host immune system $[11,17]$ and, in vitro, it has been shown that the drug increases interactions between immune cells and filarial parasites [12, 13]. Such an involvement might result from a direct effect of ivermectin on the mammalian immune system, or from the drug interfering with the immunomodulation produced by the parasite, or a combination of the two. Previous reports have shown that ivermectin inhibits secretion, of both proteins and extracellular vesicles, by $B$. malayi $\mathrm{Mf}[32,33]$; the experiments described here were designed to test the possibility that administration of ivermectin, at the dose given in mass drug administration programmes, has in addition a direct effect on human cellular immunity. The study was limited in size, being originally designed to provide preliminary evidence for further and more detailed studies, but we detected no evidence for any such effect. We would not have been able to detect subtle alterations in cytokine expression or gene expression but, given the 


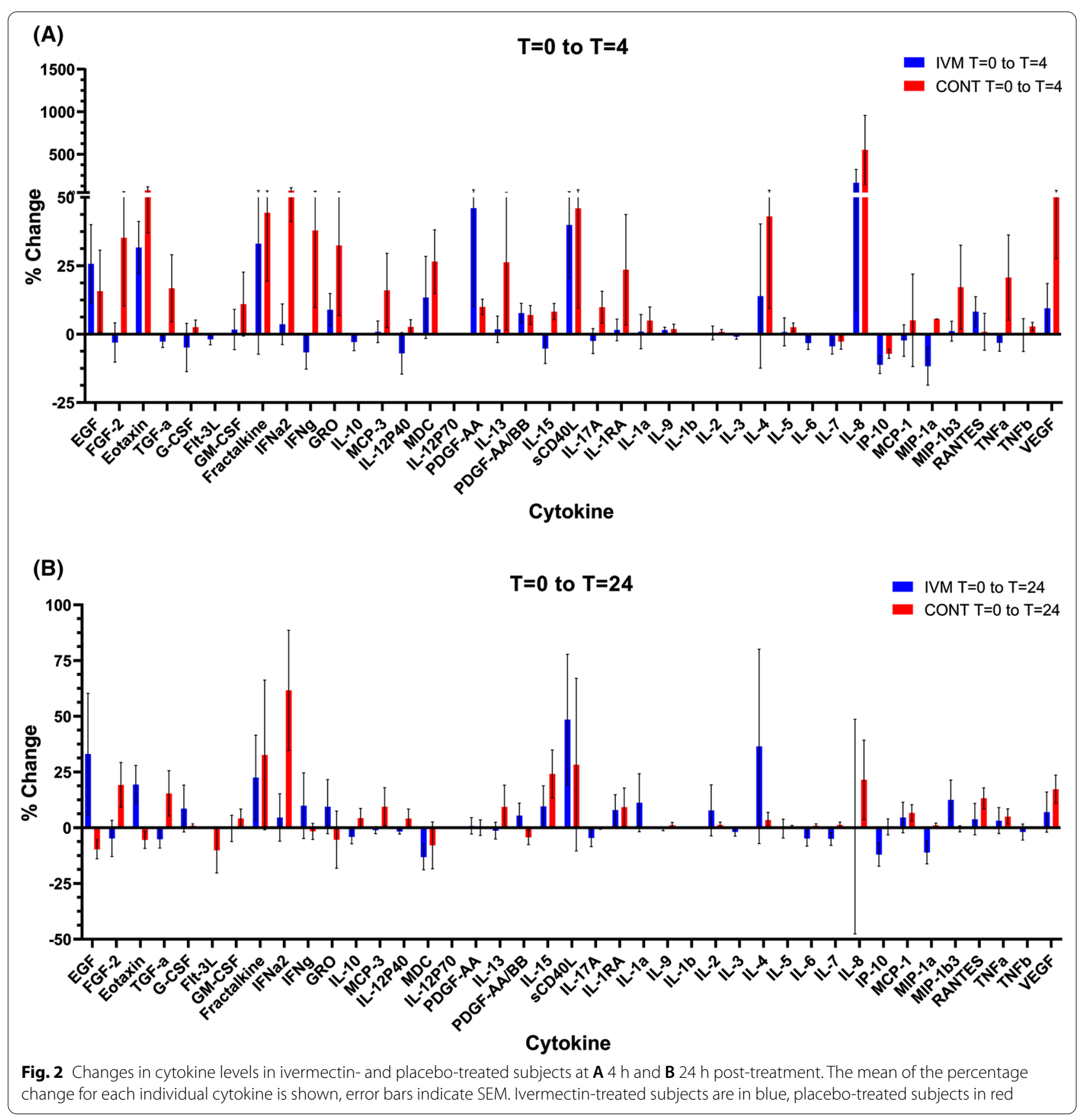

extraordinary efficacy of ivermectin treatment, if this is dependent on inducing changes in the host immune response, we believe that these should have been evident in this study.

These experiments focused on PBMC and PMN as we have previously found that these cell types have the ability to interact with $\mathrm{Mf}$ in vitro, killing the parasites under some, but not all, circumstances $[15,16]$. The complete blood counts confirmed that ivermectin did not cause any changes in the number of circulating leukocytes of any type, including eosinophils, which are frequently implicated in anti-helminth immune responses. Assessment of the effect on cytokines and chemokines was complicated by the fact that the levels of many were lower than the limits of detection of the Luminex assay, and by the variation in these levels within the control individuals. 


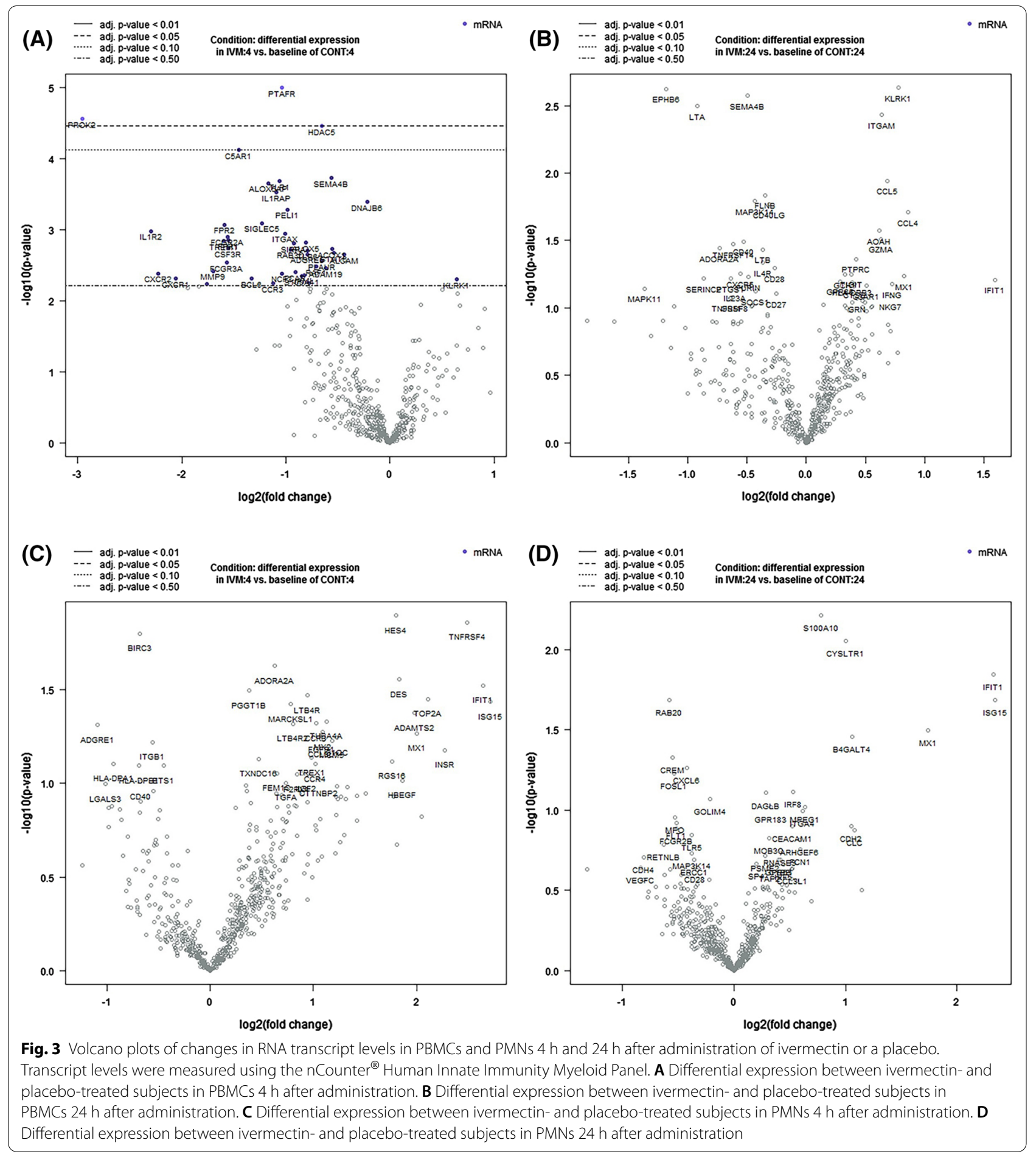

For some analytes, there seemed to be a diurnal variation, as previously reported [37-39], as the levels at 0 and $24 \mathrm{~h}$ were similar, whereas those at $4 \mathrm{~h}$ varied. However, it was not possible to distinguish any specific changes due to the drug treatment. There were similar results from the gene expression measurements. In the placebotreated PBMC samples, we found several transcripts to be significantly changed between pre-treatment and $4 \mathrm{~h}$ post-treatment, but those effects disappeared after $24 \mathrm{~h}$. Only three genes showed any significant variation in the 
Table 1 PBMC transcripts with a statistically significant change in expression between ivermectin- and placebo-treated samples $4 \mathrm{~h}$ after administration

\begin{tabular}{llllll}
\hline Transcript & Product & Log2 fold change & $p$-value & BY.p.value & Gene sets \\
\hline PTAFR & Platelet-activating factor receptor & -1.04 & $1.01 \mathrm{E}-5$ & 0.0349 & Interferon signalling \\
PROK2 & Prokineticin 2 & -2.96 & $2.75 \mathrm{E}-5$ & 0.0403 & Angiogenesis \\
HDAC5 & Histone deacetylase 5 & -0.65 & $3.48 \mathrm{E}-5$ & 0.0403 & Growth factor signalling \\
\hline
\end{tabular}

The Benjamini-Yekutieli (BY) $p$ value is that obtained after correcting for the false discovery rate [35]

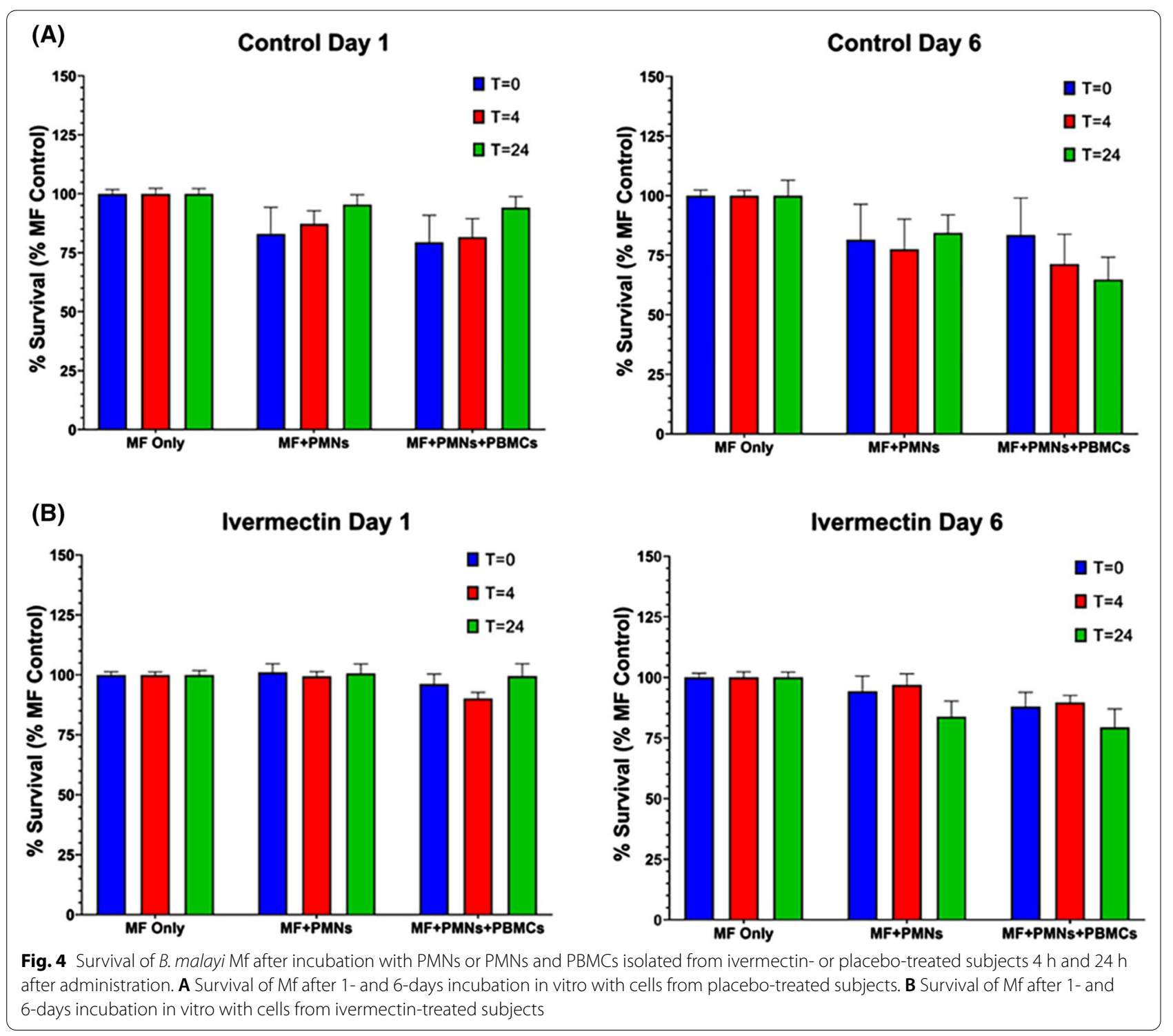

drug-treated versus control individuals, and these were all in PBMC at $4 \mathrm{~h}$ post-treatment, suggesting that any drug effect on gene expression was transient. The largest effect was an almost eightfold reduction in prokineticin 2 mRNA expression; prokineticin 2 is a pro-inflammatory peptide that is strongly upregulated in neutrophils and other inflammatory cells in response to granulocyte-colony stimulating factor or other myeloid growth factors [40]. This downregulation might therefore lead to a shortlived anti-inflammatory response; in mice, prokineticin 2 
reduces IL-10 and IL-4 production [41], so a reduction in expression in PBMCs might predict an increase in these cytokines. An increase in IL-4 was measured in ivermectin-treated individuals at $24 \mathrm{~h}$ but was not statistically significant. IL-10 levels did not change in either group. A prokineticin 2 antagonist also reduced interferon- $\gamma$ expression in spinal lymph node cells [42], and reduced IFN- $\gamma$ levels were seen in the drug-treated individuals $4 \mathrm{~h}$ post-administration compared to controls; again, these differences did not reach significance. The most statistically significant change was a smaller reduction, twofold, in platelet-activating factor receptor mRNA (PAFR). A role has been proposed for PAFR in inflammatory pathways [43], so this downregulation is also consistent with reduced inflammation. The third significant change was a small reduction in histone deacetylase 5 (HDAC5); this protein can also promote inflammation via activation of NF-kB [44]. Taken together, these changes are consistent with a potential anti-inflammatory effect of ivermectin [29], but the other changes in cytokine levels or gene expression that might be expected to accompany this were not detected. Also, no change in the ability of the PBMCs and PMNs isolated from treated individuals to kill B. malayi Mf was found. This assay uses autologous serum, so if killing were reliant on changes in compounds not tested in the Luminex assay, we should have detected it. These results suggest that any involvement of the immune system in the rapid clearance of $\mathrm{Mf}$ from the blood of treated individuals is due either to the inhibition of parasite-induced immunomodulation [32,33] or to drug-induced damage to the worms that is difficult to detect or reproduce in vitro.

\section{Conclusions}

We found no evidence to support our hypothesis that the rapid action of ivermectin against microfilaria is mediated, at least in part, via a direct effect on the host immune system. No significant changes were found in circulating cytokine levels, or in the ability of PMNs and PBMCs to kill the Mf after the drug was administered. The expression of very few genes was significantly altered.

\footnotetext{
Abbreviations

CBC: Complete blood counts; CTRU: University of Georgia Clinical and Translational Research Unit; HDAC5: Histone deacetylase 5; LF: Lymphatic filariasis; Mf: Microfilariae; mTOR: Mechanistic target of rapamycin; PAFR: Platelet-activating factor receptor; PBMC: Peripheral blood mononuclear cells; PMN: Polymorphonuclear cells.
}

\section{Supplementary Information}

The online version contains supplementary material available at https://doi. org/10.1186/s13071-021-04810-6.

Additional file 1: Table S1. Inclusion and exclusion criteria for participants recruited into the study.

Additional file 2: Table S2. NanoString results for the changes in expression of the 770 genes of the myeloid gene panel in PBMCs. In this Table all the results are compared to the Control, $\mathrm{t}=0$ sample.

Additional file 3: Table S3. NanoString results for the changes in expression of the 770 genes of the myeloid gene panel in PMNs. In this Table all the results are compared to the Control, $\mathrm{t}=0$ sample.

Additional file 4: Table S4. NanoString results for the changes in expression of the 770 genes of the myeloid gene panel in PBMCs. In this Table the changes between subjects who received ivermectin and those who received a placebo are compared at $4 \mathrm{~h}$ and $24 \mathrm{~h}$ post-treatment.

Additional file 5: Table S5. NanoString results for the changes in expression of the 770 genes of the myeloid gene panel in PMNs. In this Table the changes between subjects who received ivermectin and those who received a placebo are compared at $4 \mathrm{~h}$ and $24 \mathrm{~h}$ post-treatment.

\section{Acknowledgements}

We should like to thank the staff of the Clinical and Translational Research Unit, University of Georgia, for their help in carrying out this study, and Jamie Barber, University of Georgia College of Veterinary Medicine Cytometry Core Facility, for carrying out the Luminex analysis. Thanks also to Charlotte Nuttall for her help in the early stages of the project.

\section{Authors' contributions}

BJR and AJW were involved in conceptualization and work design. NEW and BJR performed the laboratory work. NEW carried out the data analysis. AJW wrote the manuscript. All authors read and approved the final manuscript.

\section{Funding}

This study was supported by a seed Grant from the Clinical and Translational Research Unit (CTRU) of the University of Georgia to AJW \& BJR. The University of Georgia CTRU is supported by the National Center for Advancing Translational Sciences of the National Institutes of Health under Award Number UL1TR002378. This study was also supported in part by the Emory Integrated Genomics Core (EIGC), which is subsidized by the Emory University School of Medicine and is one of the Emory Integrated Core Facilities.

\section{Availability of data and materials}

Data supporting the conclusions of this article are included within it. The results are available at ClinicalTrials.gov under record NCT03459794.

\section{Declarations}

Ethics approval and consent to participate

Experiments and informed consent procedures were approved by the Institutional Review Boards of the University of Georgia (Permit Number 2012-10769). Human subjects recruited under the guidelines of IRB-approved protocols were provided written informed consent. Human blood material was obtained from the Clinical and Translational Research Unit, University of Georgia; experiments and informed consent procedures were approved by the Institutional Review Boards of the University of Georgia (STUDY00005069).

\section{Consent for publication}

Not applicable.

Competing interests

The authors declare that they have no competing interests.

Author details

'Department of Infectious Diseases, University of Georgia, Athens, GA 30602, USA. ${ }^{2}$ Center for Tropical and Emerging Global Diseases, University of Georgia, 
Athens, GA 30602, USA. ${ }^{3}$ Present Address: INRAE Centre Val du Loire, 37380 Nouzilly, France.

Received: 8 April 2021 Accepted: 25 May 2021

Published online: 05 June 2021

\section{References}

1. Gustavsen KM, Colatrella BD, McCoy T. For as long as necessary: examining 30 years of MSD's focus on achieving elimination of onchocerciasis and lymphatic filariasis. Int Health. 2018;10:i3-6.

2. Gyapong JO, Owusu IO, Vroom F, Mensah EO, Gyapong M. Elimination of lymphatic filariasis: current perspectives on mass drug administration. Res Reports Trop Med. 2018;9:25-33.

3. Molyneux DH, Bradley M, Hoerauf A, Kyelem D, Taylor MJ. Mass drug treatment for lymphatic filariasis and onchocerciasis. Trends Parasitol. 2003;19:516-22.

4. Ottesen EA. Lymphatic filariasis: treatment, control and elimination. Adv Parasitol. 2006:61:395-441.

5. Basanez MG, Pion SDS, Boakes E, Filipe JAN, Churcher TS, Boussinesq M. Effect of single-dose ivermectin on Onchocerca volvulus: a systematic review and meta-analysis. Lancet Infect Dis. 2008;8:310-22.

6. Li BW, Rush AC, Weil GJ. High level expression of a glutamate-gated chloride channel gene in reproductive tissues of Brugia malayi may explain the sterilizing effect of ivermectin on filarial worms. Int J Parasitol Drugs Drug Res. 2014;4:71-6

7. Devaney E, Howells RE. The microfilaricidal activity of ivermectin in vitro and in vivo. Tropenmedizin Und Parasitologie. 1984;35:47-9.

8. Storey B, Marcellino C, Miller M, Maclean M, Mostafa E, Howell S, Sakanari J, Wolstenholme A, Kaplan R. Utilization of computer processed high definition video imaging for measuring motility of microscopic nematode stages on a quantitative scale: "the worminator." Int J Parasitol Drugs Drug Res. 2014;4:233-43.

9. Tompkins JB, Stitt LE, Ardelli BF. Brugia malayi: in vitro effects of ivermectin and moxidectin on adults and microfilariae. Exp Parasitol. 2010;124:394-402.

10. Zahner H, Schmidtchen D. Ivermectin-induced cell-dependent lethal effects on Litomosoides carinii microfilariae in vitro. Trop Med Parasitol. 1994:45:336-40.

11. Ali MMM, Mukhtar MM, Baraka OZ, Homeida MMA, Kheir MM, Mackenzie CD. Immunocompetence may be important in the effectiveness of Mectizan ${ }^{\circledR}$ (ivermectin) in the treatment of human onchocerciasis. Acta Trop. 2002;84:49-53.

12. Zahner H, Schmidtchen D, Mutasa JA. Ivermectin-induced killing of microfilariae in vitro by neutrophils mediated by NO. Exp Parasitol. 1997;86:110-7.

13. Vatta AF, Dzimianski M, Storey BE, Camus MS, Moorhead AR, Kaplan RM, Wolstenholme AJ. Ivermectin-dependent attachment of neutrophils and peripheral blood mononuclear cells to Dirofilaria immitis microfilariae in vitro. Vet Parasitol. 2014;206:38-42.

14. Berrafato T, Coates R, Reaves BJ, Kulke D, Wolstenholme AJ. Macrocyclic lactone anthelmintic-induced leukocyte binding to Dirofilaria immitis microfilariae: influence of the drug resistance status of the parasite. Int J Parasitol Drugs Drug Res. 2019;10:45-50.

15. McCoy CJ, Reaves BJ, Giguere S, Coates R, Rada B, Wolstenholme AJ. Human leukocytes kill Brugia malayi microfilariae independently of DNAbased extracellular trap release. Plos Negl Trop Dis. 2017;11:e0005279.

16. Reaves BJ, Wallis C, McCoy CJ, Lorenz WW, Rada B, Wolstenholme AJ. Recognition and killing of Brugia malayi microfilariae by human immune cells is dependent on the parasite sample and is not altered by ivermectin treatment. Int J Parasitol Drugs Drug Res. 2018:8:587-95.

17. Wolstenholme AJ, Maclean MJ, Coates R, McCoy CJ, Reaves BJ. How do the macrocyclic lactones kill filarial nematode larvae? Invert Neurosci. 2016;16:7

18. Cully DF, Vassilatis DK, Liu KK, Paress P, Van der Ploeg LHT, Schaeffer JM, Arena JP. Cloning of an avermectin-sensitive glutamate-gated chloride channel from Caenorhabditis elegans. Nature. 1994:371:707-11.

19. Wolstenholme AJ. Glutamate-gated chloride channels. J Biol Chem. 2012:287:40232-8.
20. Wolstenholme AJ, Rogers AT. Glutamate-gated chloride channels and the mode of action of the avermectin/milbemycin anthelmintics. Parasitology. 2005;131:S85-95.

21. Arena JP, Liu KK, Paress PS, Frazier EG, Cully DF, Mrozik H, Schaeffer JM. The mechanism of action of avermectins in Caenorhabditis elegans-correlation between activation of glutamate-sensitive chloride current, membrane-binding, and biological activity. J Parasitol. 1995;81:286-94.

22. Atif M, Smith JJ, Estrada-Mondragon A, Xiao X, Salim AA, Capon RJ, Lynch JW, Keramidas A. GluCIR-mediated inhibitory postsynaptic currents reveal targets for ivermectin and potential mechanisms of ivermectin resistance. PloS Pathog. 2019;15:e1007570.

23. McCavera S, Rogers AT, Yates DM, Woods DJ, Wolstenholme AJ. An ivermectin-sensitive glutamate-gated chloride channel from the parasitic nematode, Haemonchus contortus. Mol Pharmacol. 2009;75:1347-55.

24. Estrada-Mondragon A, Lynch JW. Functional characterization of ivermectin binding sites in alpha1 beta2 gamma2L GABA(A) receptors. Front Mol Neurosci. 2015;8:55

25. Alam S, Laughton DL, Walding A, Wolstenholme AJ. Human peripheral blood mononuclear cells express GABA receptor subunits. Mol Immunol. 2006:43:1432-42.

26. Mealey KL. Therapeutic implications of the MDR-1 gene. J Vet Pharmacol Ther. 2004;27:257-64

27. Chen IS, Kubo Y. Ivermectin and its target molecules: shared and unique modulation mechanisms of ion channels and receptors by ivermectin. J Physiol. 2018;596:1833-45.

28. Laing R, Gillan V, Devaney E. Ivermectin_old drug, new tricks? Trends Parasitol. 2017:33:463-72

29. Ventre E, Rozieres A, Lenief V, Albert F, Rossio P, Laoubi L, Dombrowicz D, Staels B, Ulmann L, Julia V, Vial E, Jomard A, Hacini-Rachinel F, Nicolas JF, Vocanson M. Topical ivermectin improves allergic skin inflammation. Allergy. 2017;72:1212-21.

30. Heidary F, Gharebaghi R. Ivermectin: a systematic review from antiviral effects to COVID-19 complementary regimen. J Antibiot. 2020;73:593-602

31. King CR, Tessier TM, Dodge MJ, Weinberg JB, Mymryk JS. Inhibition of human adenovirus replication by the importin a/ $\beta 1$ nuclear import inhibitor ivermectin. J Virol. 2020;94:e00710-20.

32. Harischandra H, Yuan W, Loghry HJ, Zamanian M, Kimber MJ. Profiling extracellular vesicle release by the filarial nematode Brugia malayi reveals sex-specific differences in cargo and a sensitivity to ivermectin. PLoS Negl Trop Dis. 2018;12:e0006438.

33. Moreno Y, Nabhan JF, Solomon J, Mackenzie CD, Geary TG. Ivermectin disrupts the function of the excretory-secretory apparatus in microfilariae of Brugia malayi. Proc Natl Acad Sci USA. 2010;107:20120-5.

34. Ricciardi A, Bennuru S, Tariq S, Kaur S, Wu W, Elkaloun AG, Arakelyan A, Shaik J, Dorward DW, Nutman TB, Semnani RT. Extracellular vesicles released from the filarial parasite Brugia malayi downregulate the host mTOR pathway. PLoS Negl Trop Dis. 2021;15:e0008884

35. Benjamini Y, Yekutieli D. The control of the false discovery rate in multiple testing under dependency. Ann Stats. 2001;29:1165-88.

36. Schirmer M, Kumar V Netea MG, Xavier RJ. The causes and consequences of variation in human cytokine production in health. Curr Opin Immunol. 2018:54:50-8.

37. Gibbs JE, Blaikley J, Beesley S, Matthews L, Simpson KD, Boyce SH, Farrow SN, Else KJ, Singh D, Ray DW, Loudon ASI. The nuclear receptor REVERB alpha mediates circadian regulation of innate immunity through selective regulation of inflammatory cytokines. Proc Natl Acad Sci USA. 2012:109.582-7.

38. Park S, Kim K, Bae IH, Lee SH, Jung J, Lee TR, Cho EG. TIMP3 is a CLOCK-dependent diurnal gene that inhibits the expression of UVBinduced inflammatory cytokines in human keratinocytes. FASEB J. 2018:32:1510-23.

39. Petrovsky N, McNair P, Harrison LC. Diurnal rhythms of pro-inflammatory cytokines: regulation by plasma cortisol and therapeutic implications. Cytokine. 1998;10:307-12.

40. Monnier J, Samson M. Cytokine properties of prokineticins. FEBS J. 2008:275:4014-21. 
41. Franchi S, Giannini E, Lattuada D, Lattanzi R, Tian H, Melchiorri P, Negri L, Panerai AE, Sacerdote $P$. The prokineticin receptor agonist BV8 decrease $\mathrm{IL}-10$ and IL-4 production in mice splenocytes by activating prokineticin receptor-1. BMC Immunol. 2008;9:60.

42. Abou-Hamdan M, Costanza M, Fontana E, Di Dario M, Musio S, Congiu C, Onnis V, Lattanzi R, Radaelli M, Martinelli V, Salvadori S, Negri L, Poliani PL, Farina C, Balboni G, Steinman L, Pedotti R. Critical role for prokineticin 2 in CNS autoimmunity. Neurol Neuroimmunol Neuroinflam. 2015;2:e95.

43. Liu G, Mateer SW, Hsuz A, Goggins BJ, Tay H, Mathe A, Fan KN, Neal R, Bruce J, Burns G, Minahan K, Maltby S, Fricker M, Foster PS, Wark PAB, Hansbro PM, Keely S. Platelet activating factor receptor regulates colitis-induced pulmonary inflammation through the NLRP3 inflammasome. Mucosal Immunol. 2019;12:862-73.

44. Zhao YH, Ma GR, Yang XG. HDAC5 promotes Mycoplasma pneumoniaeinduced inflammation in macrophages through NF-kappa B activation. Life Sci. 2019:221:13-9.

\section{Publisher's Note}

Springer Nature remains neutral with regard to jurisdictional claims in published maps and institutional affiliations.
Ready to submit your research? Choose BMC and benefit from:

- fast, convenient online submission

- thorough peer review by experienced researchers in your field

- rapid publication on acceptance

- support for research data, including large and complex data types

- gold Open Access which fosters wider collaboration and increased citations

- maximum visibility for your research: over 100M website views per year

At BMC, research is always in progress.

Learn more biomedcentral.com/submissions 